\title{
The Structural Model of Knowledge Management in Universities
}

\author{
Fattah Nazem \\ Department of Education, Roudehen Branch, Islamic Azad University, Roudehen, Iran
}

\begin{abstract}
The purpose of the present study was to provide a structural model of knowledge management in universities based on managers' entrepreneurship. The population of the research included all employees of Islamic Azad University (IAU). The research sample consisted of 530 managers and three employees under their supervision (totally 1590 employees) selected using stratified and cluster random sampling method. The research instruments were two questionnaires which were administered in 78 IAU branches and education centers: Sallis and Jones's (2002) Knowledge Management Questionnaire $(\alpha=0.97)$ and a researcher-made questionnaire for Managers' Entrepreneurship $(\alpha=$ 0.90). The results of path analysis using LISREL software indicated that dimensions of managers' entrepreneurship had a direct effect on knowledge management with the indices of 0.71. The model also showed that the factor of time management in managers' entrepreneurship had the highest direct effect on the knowledge management.
\end{abstract}

\section{Introduction}

In the early years of the third millennium and amid perpetual environmental changes, the higher education has witnessed metamorphosis, a process which requires the universities to be more dynamic, transparent, and competitive. Furthermore, with the profoundly shifting position of higher education due to multiple factors such as, public opinion, and shifting political ideologies, it is crucial that higher education institutions learn to effectively manage and utilize the knowledge by which they improve their strategic position and ultimately bolster their organizational legitimacy. As environmental turbulence increases and competition intensifies, higher education institutions will need to engage and respond to the pressures of the marketplace [1].

In their book entitled "Knowledge management in education", Sallis \& Jones offered a useful knowledge management self-assessment checklist with scoring elements such as vision and mission, strategy, organizational culture, intellectual capital, learning organization, leadership and management, teamwork and learning communities, sharing knowledge, knowledge creation, and digital sophistication for the organization. Vision and mission refer to having vision as a knowledge-based organization and sharing it with the stakeholders and the mission as the knowledge creator and translating it into practical strategies. Strategy refers to developing modeled scenarios and applying them in management. Organizational culture refers to the different dimensions of culture including the creating, centralizing, sharing, and recognizing organizational culture as a key competence. Intellectual capital includes recognizing the value of intellectual assets and codifying its tacit knowledge. Under learning organization, organization should create continuous learning, define skills to create new knowledge, recognize EQ and its influences, encourage creative thinking, and promote action learning both for individuals and teams. In leadership and management, organizations are required to have senior-management support, have knowledge leaders and managers with appropriate leadership styles, and develop strategies for promoting middle-managers. Under teamwork and learning communities, organization should encourage learning communities and knowledge teams, establish trust, and recognize the need for intellectual autonomy. The next factor "sharing knowledge" signifies that organizations ought to collect, record major organization events, and share new information, and understand competitors' knowledge management system. Knowledge creation also requires the organizations to recognize new knowledge, those known as experts, and turn it into service. Finally, in terms of digital sophistication, organizations are to develop technologies among its employees by clear technological architecture, enhancing its knowledge, and devising virtual collaborative systems and/or communities [2].

Drucker believes that managers are the most rare and most valuable resources of organizations [3]. One of the features necessary for any manager is entrepreneurship. The entrepreneur is a person who organizes, accepts, manages, and has commitment to the dangers of an economic activity. He also pinpoints a chance and, in order to take it, he establishes an organization. The process of entrepreneurship includes all duties, activities, and operations related to the pinpointing of the chance and establishing an organization in order to take such chances [4]. According to the experts in the related 
field like Koh [5], Gürol [6], Hildebrando [7], and Gillian et al., [8] entrepreneurs have various characteristics; some of these characteristics have been defined as follows:

1. The need for progress: "The need for progress" consists of tendency toward doing jobs in high standard level in order to succeed in comparative situations.

2. The center of internal control: Successful entrepreneurs believe in themselves, they do not think their success or failure is as a result of their destiny, good/bad luck, or other similar powers. They believe that failures and advancements are under their control, and they can affect the results of their performance.

3. Tendency toward risk taking: It refers to the moderate risks that can be controlled through personal attempts. Facing any kind of risk, two elements play role in creation of this concept, the first element is the extent that the entrepreneur understands the risk, and the second element is the probability of failure in case of doing unsuccessful activity.

4. The need for independence: This element has been emphasized as a very stimulating power. In fact, the need for independence can be defined as: "control over one's destiny", "doing something for oneself", "being the master of oneself".

5. Creativity: It refers to the ability of creating new ideas which may lead to new products or services.

6. Competitiveness: Ability of an organization to offer services at prices that are competitive and provide enough returns on the resources used in producing them.

7. Self confidence: It means how secure a person is in their own decisions and actions.

8. Realistic: It means willing to see things as they really are and deal with them sensibly.

9. Persistency: It refers to the state of being insistent or uninterrupted existence or succession.

10. Time management: It means you control your time and work and do not let those affairs and events handle you.

11. Openness to criticism: The word criticism means looking for or pointing out faults. Therefore, openness to criticism is defined as a characteristic to accept others' opinions about one's faults.

12. Being vivacious: It means the quality or state of being lively in temper or conduct.

13. Being purposeful: It means having a purpose or aim. It also means being full of determination.

Among other factors like communication, caring, credibility, and confidence, creativity is one of the significant skills of the leaders which encourages employees to accept challenges and to take risks [9]. Creativity, along with other features of qualitative leadership, helps create a culture that encourages knowledge creation and knowledge sharing, open communication, support learning, and tolerate failure [10].

Mahmood and $\mathrm{Yu}$ [11] also underlined the role of some factors like macro environment, policy framework, institutional support, and performance of entrepreneurial activities in the emergence of a knowledge-based economy. The results of another study by Vincent [12] showed that overall knowledge management actions have a close correlation with the members' perception of leadership. She underlined the role of leadership behaviours like reward equity, capable management, creative leadership, and visionary leadership as having moderate positive and significant relationship with knowledge management actions. This again underlies the position of creativity as one of the major features of any entrepreneur. Vincent also reaffirms that leadership is very important in knowledge management efforts. Team leaders, by using their transactional and transformational behaviours, may help facilitate the collective knowledge management actions.

\section{Research Questions}

1. What is the structural model of the knowledge management based on managers' entrepreneurship in universities?

2. Which variables have the highest and the lowest effect on knowledge management?

3. How much is the goodness of fit in this research?

\section{Method of the Study}

The research methods which were used in this study are: library research to access the theoretical framework and the related literature; Survey method to collect, classify, describe, and analyze the data. The population under investigation in this study consist of official staffs who work in 420 branches and educational centers in 14 zones of Islamic Azad University. In order to estimate the least volume of sample, $n=\frac{z^{2} \sigma^{2}}{d^{2}}$ Regarding the minimum sample required for the managers' group which was estimated as 530 and staff group as 1590 (three staff for each manager), managers' entrepreneurship questionnaire was administered to the managers. Also, the knowledge management questionnaire was administered to the staff in 78 branches and educational centers. In order to select the research sample, two methods of stratified and cluster random sampling were used.

The research instruments were as follows: Sallis and Jones's Knowledge Management Questionnaire [2] which consisted of 42 items with ten underlying constructs of vision and mission, strategy, 
organizational culture, intellectual capital, learning organization, leadership and management, teamwork and learning communities, sharing knowledge, knowledge creation and digital sophistication with Cronbach's Alpha of 0.97; and a researcher-made questionnaire for managers' entrepreneurship which consisted of 58 items with dimensions of need for progress, need for independence, risk taking, creativity, time management, having steadiness, tendency to aim, tendency to challenge, self confidence, internal control center, accepting criticism, realism and being energetic with the Cronbach's Alpha of 0.90. The obtained data were analyzed through path analysis using LISREL software.

\section{Findings of the Study}

The data collected from the administration of the instruments were analyzed. These data included the different indexes of central tendency, variability and the distribution of both groups, the managers' scores obtained from the questionnaire of managers' entrepreneurship and its components and the staff's scores obtained from knowledge management questionnaire and their related components. The distribution of the managers' and the staff's scores in the given variables had tendency toward normality.

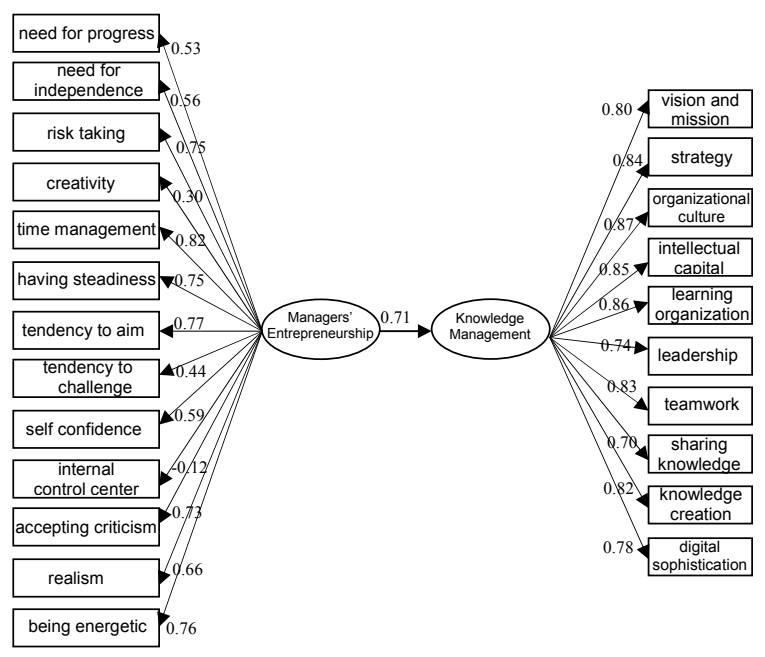

Figure 1. Path analysis model for components of managers' entrepreneurship with knowledge management

As shown in Figure 1, the Lambda rate of external latent variable of managers' entrepreneurship components were 0.53 for need for progress, 0.56 for need for independence, 0.75 for risk taking, 0.30 for creativity, 0.82 for time management, 0.75 for having steadiness, 0.77 for tendency to aim, 0.44 for tendency to challenge, 0.59 for self confidence, -0.12 for internal control center, 0.73 for accepting criticism, 0.66 for realism,
0.76 and for being energetic whose accumulation form the managers' entrepreneurship variable with the effectiveness rate of 0.71 . It means that $0.71 \%$ of the variation in the dependant variable of knowledge management is explained by a collection of these indices. The variable of time management indicates the highest amount of internal consistency in the external latent variable.

The Lambda rate of internal latent variable of knowledge management components were 0.74 for leadership and management, 0.83 for teamwork and learning communities, 0.70 for sharing knowledge, 0.82 for knowledge creation, 0.78 for digital sophistication, 0.80 for vision and mission, 0.84 for strategy, 0.87 for organizational culture, 0.85 for intellectual capital, and 0.86 for learning organization whose accumulation form the knowledge management variable. The variable of organizational culture indicates the highest amount of internal consistency in the internal latent variable. Since the model's goodness of fit index is 0.92 , it can be stated that it has an acceptable fit. The calculated index indicates the direct effect of managers' entrepreneurship components on knowledge management.

The following table presents the indices related to the model's fit:

Table 1. Model's fit indices

\begin{tabular}{|l|l|l|}
\hline Index & Rate & Interpretation \\
\hline $\begin{array}{l}\text { Lewis-Tucker } \\
\text { normed fit index) }\end{array}$ & 0.91 & $\begin{array}{l}\text { High fit (more than } \\
0.90)\end{array}$ \\
\hline $\begin{array}{l}\text { Bentler-Bonett's (Normed } \\
\text { fit index) }\end{array}$ & 0.91 & $\begin{array}{l}\text { High fit (more than } \\
0.90)\end{array}$ \\
\hline Hoelter & 0.79 & $\begin{array}{l}\text { High fit (more than } \\
0.70)\end{array}$ \\
\hline $\begin{array}{l}\text { Root Mean Square Error } \\
\text { (RMSE) }\end{array}$ & 0.046 & $\begin{array}{l}\text { High fit (less than } \\
0.05)\end{array}$ \\
\hline GFI & 0.92 & $\begin{array}{l}\text { High fit (more than } \\
0.90)\end{array}$ \\
\hline
\end{tabular}

The five indices of goodness of fit indicate presented model's fit and empirical data. Therefore, desirability adaptation is provided for the designed model and empirical data and can approve it as an appropriate model for the knowledge management.

\section{Discussion}

The results of path analysis method revealed that the dimensions of entrepreneurship had positive impact on knowledge management. The findings of the present study, furthermore, indicated the influential role of entrepreneurship on knowledge management. Pierre-Andre [13] pinpoints entrepreneurship and entrepreneurial activities in knowledge economy. In their study, Guadamillas et al. [14] found out that creating and enhancing knowledge can underpin the development of the firm 
through corporate entrepreneurship. Mahmood \& Yu [11] also thought that knowledge-based economy depends on several factors including entrepreneurial activities. However, only recently researchers have identified the role of leaders at multiple levels in the various organizational learning processes, and the role of leaders in the processes of managing knowledge in organizations. Vincent [12] showed that overall knowledge management actions have a close correlation with the leadership and underlined the role of leadership behaviours like reward equity, capable management, creative leadership, and visionary leadership as having relationship with knowledge management actions. The essence of all entrepreneurial activities is creativity which is itself one of the features of creative entrepreneurship. Vincent believes that leadership is the key for knowledge management efforts. Vincent also reaffirms that leadership is very important in knowledge management efforts. Team leaders, by using their transactional and transformational behaviours, may help facilitate the collective knowledge management actions. Marchand [15] also highlights the impact of leader on using and persisting on creativity in knowledge management. Among other factors, creativity is one of the significant skills of the leaders which encourage employees to accept challenges and to take risks [9]. Creativity, along with other features of qualitative leadership, helps create a culture that encourages knowledge creation and knowledge sharing, open communication, support learning, and tolerate failure [10]. Besides, in such studies as Chua [10], and Koch et al. [16], the role of managers and leadership are pinpointed in successful knowledge management.

Knowledge management is now widely recognized as a competitive advantage and an increasing number of organizations are incorporating the knowledge management strategy [17]. According to Koulopoulos and Frappaolo [18], knowledge management is a critical business strategy which enables an organization to leverage its most precious resources, collective knowledge, talent and experiences to accelerate the rate at which it handles new market challenges and opportunities.

Recent developments in the organizational knowledge literature [19] stress the importance of knowledge management to build a sustainable competitive advantage [20] and to the importance of leadership for the success of information and knowledge management projects. More specifically, the growing information systems literature on information and knowledge management has repeatedly stress the lack of leadership support for the failure of many knowledge management projects [21] and the importance of leadership in effective knowledge management [22]. The results of the studies conducted in the field reiterate that success in performing knowledge management models needs managers who are creative so that, in the complicated and competitive world, they can solve the organization's problems creatively.

\section{Conclusions}

The need for management and leadership is vital and sensible in all fields of social activities. Without effective leadership and guidance, material and human resources are doomed to decrease and destruction, while the managers of universities as people who are in charge of organizations and university branches are considered as the main and determining factor in preparing and supplying the human resources required by other organizations which provide services or products in the society. The appointment of entrepreneurship managers in universities can help manage the knowledge management more efficiently. Lee [23] underlines the significance of knowledge management in managing scientific bodies in higher education institutes. It is also suggested that the research projects as this are to be endorsed in all branches of Islamic Azad University (IAU) to upgrade the knowledge management. With the effective role of universities in the economic, social, political, and cultural development, it is suggested that this study can also be carried out in other universities all around the world so as to practically take giant steps in the knowledge management.

\section{Acknowledgements}

This paper is extracted from a research project sponsored by the research department of the Islamic Azad University, Roudehen Branch to whom I owe a debt of gratitude.

\section{References}

[1] A. Levine, "The remaking of the American university", Innovative Higher Education, 2001, 25(4), 253-267.

[2] Sallis, E. \& Jones, G. Knowledge management in education, Kogan page Limited, London, 2002.

[3] Drucker, P. F. The practice of management, Harper and Row, New York, 1954.

[4] Bygrave, W., The portable MBA in Entrepreneurship, N. Y.: John Wiley \& Sons Inc, 1994.

[5] H. C. Koh, "Testing hypotheses of entrepreneurial characteristics", A study of Hong Kong MBA student, Journal of managerial psychology, 1996, 11 (3), 12-25.

[6] Y. Gürol, "Entrepreneurial characteristics amongst university students.", Education + Training, 2006, 48(1), 25- 38 . 
[7] Hildebrando, V., B., Assessing entrepreneurial characteristics in a Brazilian training, [Dissertation Abstract Ph.D.], Union Institute and University, 2003.

[8] S. M. Gillian, J. Weerawardena, K.Camegie, "Social entrepreneurship: Towards conceptualization and measurement", American Marketing Association, Conference Proceedings, Chicago, 2002, vol. 13, p. 5.

[9] Sashkin, M., Rosenbach, W., \& Sashkin, M.G. The leadership profile: Psychometric development of a leadership assessment tool and its use in leadership development. Unpublished working paper, The George Washington University, 1998.

[10] A. Chua, "The influence of social interaction on knowledge creation", Journal of Intellectual Capital, 2002, 3(4), 375-392.

[11] A. Mahmood, C. M. Yu, "E-entrepreneurship in knowledge economy: Implications for the Asia- Pacific economies", The Business Review, Cambridge, 2005, 4(1), 153- 160 .

[12] Vincent, C. Leadership in a knowledge society: An examination of the relationship between perceptions of leadership and knowledge management actions using a social action theory approach, [Ph.D. dissertation], George Washington University, 2006.

[13] J. Pierre- Andre, "A theory of local entrepreneurship in the knowledge economy", Reference and Research Book News, 2008, 23(2), 322.

[14] F. Guadamillas, M. Donate, J. D. S. Pablo, "Knowledge management for corporate entrepreneurship and growth: a case study", Knowledge and Process Management. Chichester, 2008, 15(1), 32.

[15] Marchand, N. Organizational effectiveness through knowledge management strategies at kingsgate Port of Entry, Canada-Border Services Agency. [Dissertation Abstract M. A.]. Canada: Royal Roads University , Canada, 2009.

[16] H. Koch, D. Pardice, B. Chase, Y. Guo, "An investigation of knowledge management within a university IT group", Information Resource Management Journal, 2002, 15(1), 13-21.

[17] Jr., F. M. R. Armbrecht, F. B. Chapas, C. C. Chappelow, G. F. Farris. "Knowledge management in research and development", Research Technology Management, 2001, 44(4), 28- 48.
[18] Koulopoulos, T. M., \& Frappaolo, C. Smart things to know about knowledge management., Capstone Publishing Limited, Oxford U. K, 2000.

[19] R. M. Grant, "Toward a knowledge-based theory of the firm", Strategic Management Journal, 1996, 17 (2), 09-22.

[20] W. C. Bogner, P. Bansal, "Knowledge management as the basis of sustained high performance", The Journal of Management Studies, 2007, 44 (1), 165-88.

[21] Davenport, T.H., De Long, D.W. \& Beers, M.C. Successful knowledge management projects, Sloan Management Review, Winter, 1998.

[22] K. Bell De Tienne, G. Dyer, C. Hoopes, S. Harris, "Toward a model of effective knowledge management and directions for future research: culture, leadership, and CKOs", Journal of Leadership and Organizational Studies, 2004, 10 (4), 26-43.

[23] Lee, H. Y., Department chair's perceptions of knowledge management strategies in colleges of education: Measurement of performance by organizational factors. [Dissertation Abstract Ed. D.]. United States Illinois: Northern Illinois University, 2007. 